\title{
ASSESSMENT OF EARLY SEASON AGRICULTURAL DROUGHT USING REMOTE SENSING
}

\author{
Bhaskar R. Nikam ${ }^{1 *}$, S. P. Aggarwal ${ }^{1}$, Praveen K. Thakur ${ }^{1}$, Vaibhav Garg ${ }^{1}$, Sourav Roy², Arpit Chouksey ${ }^{1}$, Pankaj R. Dhote ${ }^{1}$, \\ Prakash Chauhan ${ }^{1}$ \\ ${ }^{1}$ Scientist, WRD, IIRS, 4, Kalidas Road, Dehradun, Uttarakhandn India; ${ }^{2}$ Former PGD Student, WRD, IIRS, 4, Kalidas Road, \\ Dehradun-248001;
}

KEY WORDS: Meteorological Drought, SPI, Agricultural Drought, SASI, Agricultural Stress

\begin{abstract}
:
Drought is a stochastic natural hazard that is caused by intense and persistent shortage of precipitation. The initial shortage of rainfall subsequently impacts the agriculture and hydrology sectors. Marathwada region of India comes under highly drought prone area in the country. Recent times have shown the increase in occurrence of agricultural drought in the non-monsoon season. The deviation from normal rainfall in the month of October causes soil moisture deficit which triggers an agricultural drought in the early-Rabi season. The traditional remote sensing based agricultural drought monitoring indices lack in identifying the early-season (ES) drought. An attempt has been made in the present study, to map ES agricultural drought in the Aurangabad district of Marathwada region using remote sensing. The meteorological deficit in the month of October, has been assessed using Standardized Precipitation Index (SPI). Impact of meteorological fluctuations on agricultural system in terms of dryness/wetness was evaluated using the Shortwave Angel Slope Index (SASI) derived using MODIS (Terra) Level-3, 8 daily, surface reflectance data for the October months of 2001-2012. It was observed that the area experiences moderate to severe drought 5 times with 12 years of study period (2001-2012). SASI and its parameters were estimated for each week of October month. SASI maps were further classified in four categories viz. moist vegetation; dry vegetation; moist soil and dry soil. The detailed analyses if these maps indicate that agricultural stress occurs in this area even if there is no meteorological stress. However, whenever, there is meteorological stress the area under agricultural stress exceeds more than $50 \%$ of the study region. A frequency distribution map of ES drought was prepared to identify the most drought prone area of the district and to alternately identify the irrigated area of the district.
\end{abstract}

\section{INTRODUCTION}

Drought means a sustained, extended deficiency in precipitation (WMO, 1986). Palmer (1965) described drought as a significant deviation from the normal hydrologic conditions of an area and The Food and Agriculture Organization (FAO, 1983) of the United Nations defines a drought as a hazard, the percentage of years when crops fail from the lack of moisture. Drought occurs over most parts of the world, even in wet and humid regions. Droughts draw increasing attentions from ecologists, environmentalists, meteorologists, hydrologists, geologists as well as agricultural scientists due to their huge impacts on ecology, environment, hydrology and agriculture and now a days drought monitoring and early warning system development becomes an important area of research. Morid et al. (2006) said drought monitoring is an essential component of drought risk management and it is normally performed using various drought indices that are effectively continuous functions of rainfall and other hydro-meteorological variables. Drought indices are developed and meant for decision making and are broadly classified into three categories, meteorological; hydrological and agricultural drought indices.

Some widely used and advanced meteorological drought indices are Rainfall Anomaly Index, Palmer Drought Severity Index, Bhalme and Mooley Drought Index, Drought Severity Index, Standardized Precipitation Index (SPI), Effective Drought Index and Reconnaissance Drought Index. However, SPI is the most dominantly used meteorological drought index globally (Dogan et al., 2012; Vangelis et al. 2013; Zarch et al. 2015, Padhee et al.,
2016, Padhee et al., 2017; Awsathi et al., 2018). Agriculture is very crucial sector for the well existence of the socio-economic situations in large part of the world and drought is a potential threat to agricultural sustenance. The necessity of monitoring the drought in agriculture sector led to development of various indices with explicit characteristics for agricultural drought assessment. Some of the agricultural drought indices are moisture adequacy index, crop moisture index, crop specific drought index, soil moisture and evapotranspiration deficit indices. Leng et al. (2015) used standardized precipitation index (SPI), standardized runoff index (SRI) and standardized soil moisture index (SSWI) to assess the climate change impact on droughts from meteorological, agricultural, and hydrologic perspectives. It is of importance to investigate the response of agricultural drought to meteorological drought and its influencing factors, which could help better understand drought evolution mechanisms and facilitate agricultural drought monitoring and predictions (Huang et al. 2015). For drought monitoring, assessment and prediction, Remote sensing and GIS technologies are capable to cover the earth surface, better than traditional techniques. Several new approaches have been developed to extract information from archived and real time remote sensing data for the purpose of drought studies. The narrower spectral bandwidths in Moderate-Resolution Imaging Spectr-oradiometer (MODIS) for the red band and NIR band, which have increased sensitivity towards chlorophyll and water vapor absorption respectively, makes it more efficient for thematic applications (Huete et al., 2002; Wilhite, 2002; Vangelis et al., 2013; Rhee et al. (2010). Khanna et al. (2007) proposed a methodology for assessment of agriculture drought using newly developed

\footnotetext{
$1 *$ corresponding author: bhaskarnikam@iirs.gov.in
} 
Shortwave Angle Slope Index (SASI) index that refers to soil and vegetation moisture based on NIR ( $858 \mathrm{~nm}$ ) and SWIR (1240 and $1640 \mathrm{~nm})$ MODIS bands. SASI parameterizes the general shape of the NIR-SWIR part of the spectrum. Das et al. (2012) derived shortwave angle slope index (SASI) from near infrared (NIR), shortwave infrared 1 (SWIR1) and shortwave infrared 2 (SWIR2) bands of Moderate Resolution Imaging Spectroradiometer (MODIS) 500-m 8-day composite images in three meteorological sub-divisions of India. The SASI, sensitive to surface wetness, was found to be strongly correlated with rainfall and its seasonal profiles were able to distinguish the early season drought incidents. Comparison between normalized difference vegetation index (NDVI) and SASI showed that during the beginning of the crop season, SASI was relatively better in discriminating the surface dryness conditions prevailing in different years.

Marathwada region of Maharashtra, India comes under high drought prone area in the country, with drought occurrence probability as high as $50 \%$. Much work has been done towards identification, characterization and forecasting of meteorological droughts in this region. However, recent times have shown the increase in occurrence of agricultural drought in the nonmonsoon season, due to variation in rainfall or improper management irrigation water. The water requirement of crops in early Rabi (winter) season in the Marathwada region is mainly met by the residual moisture content in the soil from the rain occurred in the month of October. The deviation from normal rainfall in the month of October may cause soil moisture deficit which will trigger an agricultural drought in the subsequent months (early-Rabi season). Traditional remote sensing based indices used for agricultural drought monitoring lack in identifying the early-season (ES) drought. Furthermore, the ES agricultural drought assessment is challenging task due to difficulties in the generation of operational soil moisture products at farm scale. Hence, an attempt has been made in the present study to identify and map agricultural drought in the Aurangabad district of Marathwada region, India using remote sensing inputs. The weekly SASI maps were further used to map the irrigated area of the district using sensitivity analysis between meteorological drought index and SASI.

\section{STUDY AREA}

Aurangabad district is one of the 8 districts of Marathwada region of Maharashtra, India. Geographically the district extends between $19^{\circ}$ and $20^{\circ}$ North, and $74^{\circ}$ and $76^{\circ}$ East (Figure 1) covering $10,100 \mathrm{~km}^{2}$ area, out of which $141.1 \mathrm{~km}^{2}$ is urban area and $9,958.9 \mathrm{~km}^{2}$ is rural. Aurangabad District is located mainly in the Godavari River Basin and partly in the Tapi River Basin. The district receives major portion of its annual rainfall during the monsoon months viz. June to September. The average annual rainfall of Aurangabad District is $734 \mathrm{~mm}$, and the temperature ranges between 5-46 degrees Celsius.

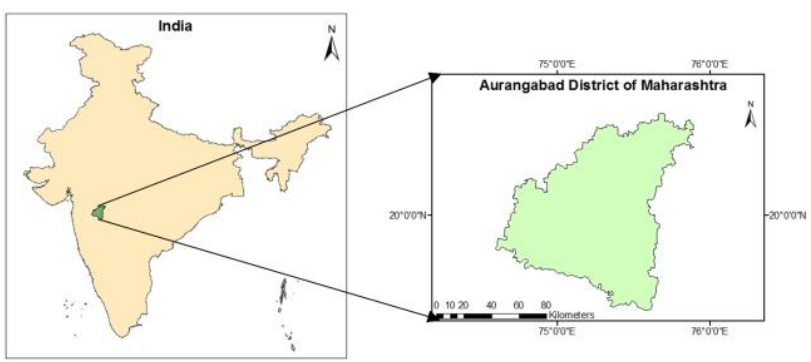

Figure 1: Location of the Aurangabad District of Maharashtra

\section{METHODOLOGY}

The methodology followed for mapping, monitoring and analyzing early-season agriculture drought in the Aurangabad district is shown in Figure 2 and briefly described in this section.

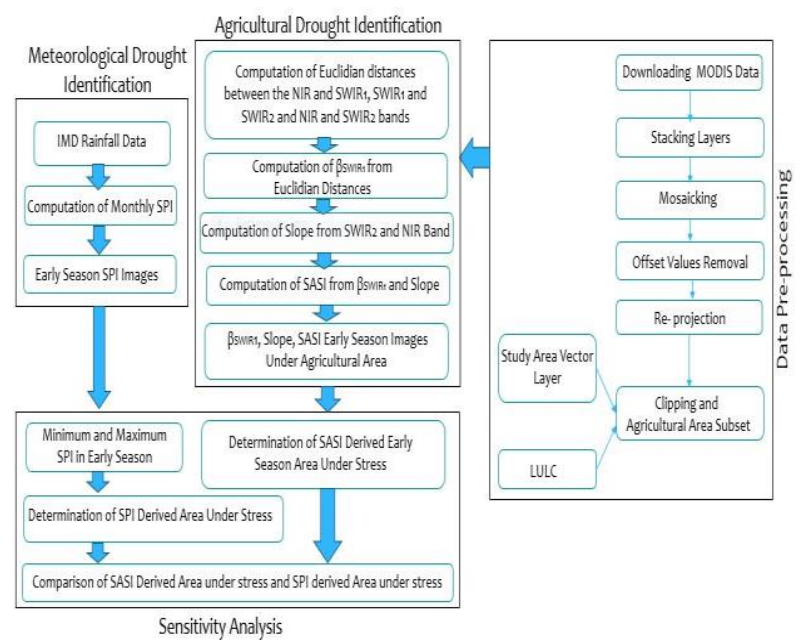

Figure 2: Methodology Flow Chart

\subsection{Data Used}

The early Rabi season of year (October month) of 2001 to 2012 was selected as study period. The main reasons for selecting the October month are; Rabi season starts from the month of October which is the pre-sowing period of Rabi crops and the rainfall received in the Rabi season is mainly in the month of October, most of the cases all other months of Rabi season have zero rainfall or less than 1 percent of total annual rainfall and although agricultural stress may occur even if there is no meteorological drought but the impact of early season rainfall on the Agricultural stress can't be ignored.

MODIS Surface Reflectance Terra 8-Day L3 Global 500m data was used in this study. It is a seven-band product computed from the MODIS Level 1B land bands $1(620-670 \mathrm{~nm}), 2$ (841-876 $\mathrm{nm}), 3$ (459-479), 4 (545-565 nm), $5(1230-1250 \mathrm{~nm}), 6$ (1628$1652 \mathrm{~nm})$, and $7(2105-2155 \mathrm{~nm})$. The Meteorological data for the study area has been procured from India Meteorological Department (IMD), Pune. It was $0.25^{\circ} \times 0.25^{\circ}$ gridded data and consisted of daily precipitation records from 1983 to 2012. The land use land cover map generated under ISRO- GBP LULC Project was used to generate agriculture mask for detailed analysis of drought.

\subsection{Calculation of Standardized Precipitation Index (SPI)}

The SPI is used in the present study to investigate variations in rainfall in terms of dryness/wetness. The SPI is calculated on the basis of the probability of the occurrence of certain amount of precipitation over multiple time scales (e.g. 1, 3, 6, 9, 12, and 24 months). In the present study, the SPI is estimated at monthly time scale. To compute SPI, historic rainfall data are fitted to a gamma probability distribution function as follows (McKee et al., 1993).

$$
\begin{aligned}
& g(x)=\frac{1}{\beta^{\alpha} \Gamma(\alpha)} x^{\alpha} e^{-x / \beta} \text { for } x>0 \\
& \Gamma(\alpha)=\sum_{0}^{\infty} x^{\alpha-1} e^{-x} d x
\end{aligned}
$$


Where, $x$ is the amount of precipitation $(\mathrm{mm})$ at certain time scale, $\alpha$ is the shape parameter, $\beta$ is the scale parameter, and $\Gamma(\alpha)$ defines the gamma function. Maximum likelihood method is used to estimate the shape parameter $\alpha$ and the scale parameter $\beta$.

Fitting the distribution to the data requires $\alpha$ and $\beta$ to be estimated. Using the approximation of Thom (1958), these parameters can be estimated as follows:

$$
\begin{aligned}
& \alpha=1 / 4 A(1+\sqrt{1+4 A / 3}) \\
& \beta=\bar{x} / \alpha
\end{aligned}
$$

for $n$ observations

$$
A=\ln (\bar{x})-1 / n \sum_{i=1}^{n} \ln \left(x_{i}\right)
$$

The cumulative probability function of the precipitation distribution is given by,

$G(x)=\int_{0}^{x} g(x) d x=\frac{1}{\beta^{\alpha} \Gamma(\alpha)} \int_{0}^{x} x^{\alpha-1} e^{-\frac{\alpha}{\beta}} d x$

The gamma distribution is undefined for $\mathrm{x}=0$. Since precipitation distribution may contain zeros, in order to account for zero value probability, the cumulative probability can be written as:

$$
H(x)=q+(1-q) G(x)
$$

Where, $\mathrm{q}$ is the probability of zero precipitation. The cumulative probability, $\mathrm{H}(\mathrm{x})$, is then transformed to the standard normal random variable $\mathrm{Z}$ with mean zero and variance one, which is the value of SPI. Following the approximate conversion provided by Abramowitz and Stegun (1965), Z, and hence SPI, is expressed as:

$$
\text { for } 0<H(x)<0.5
$$

$$
\begin{gathered}
S P I=-\left(t-\frac{c_{0}+c_{1} t+c_{2} t^{2}}{1+d_{1} t+d_{2} t^{2}+d_{3} t^{3}}\right), t=\sqrt{\ln \left(\frac{1}{H(x)^{2}}\right)} \\
\text { for } 0.5<H(x)<1.0 \\
S P I=\left(t-\frac{c_{0}+c_{1} t+c_{2} t^{2}}{1+d_{1} t+d_{2} t^{2}+d_{3} t^{3}}\right), t=\sqrt{\ln \left(\frac{1}{1-H(x)^{2}}\right)}
\end{gathered}
$$

Where, $\mathrm{c}_{0}=2.515517 ; \mathrm{c}_{1}=0.802853 ; \mathrm{c}_{2}=0.010328$ and $\mathrm{d}_{1}=$ $1.432788 ; \mathrm{d}_{2}=0.189269 ; \mathrm{d}_{3}=0.001308$.

Positive SPI values indicate greater than median precipitation, and negative values indicate less than median precipitation. Since SPI is normalized, wetter and drier climates can be represented in the same way, and wet periods can also be monitored using SPI. Classifications of the severity of dry and wet conditions based on the SPI values are listed in Table 1;

Table 1: Drought classification according to SPI values

\begin{tabular}{cc}
\hline SPI & Drought Classes \\
\hline 2 or more & Extremely wet \\
1.5 to 1.99 & Severely wet \\
1 to 1.49 & Moderately wet \\
0.99 to 0.0 & Normal \\
\hline
\end{tabular}

\begin{tabular}{cc}
\hline SPI & Drought Classes \\
\hline 0.0 to -0.99 & Near normal \\
-1 to -1.49 & Moderately dry \\
-1.5 to -1.99 & Severely dry \\
-2 and less & Extremely dry \\
\hline
\end{tabular}

\subsection{Computation of Shortwave Angle Slope Index (SASI)}

The SASI, as originally developed by Palacios-Orueta et al. (2006), is a combination of NIR, SWIR1 and SWIR2 MODIS bands. Whiting et al. (2004) demonstrated that the SWIR region could be fitted by an inverted Gaussian function that was highly correlated to moisture content in soils. SASI emulates the general shape of this part of the spectrum. To accomplish this, we evaluated a triangle with vertices at R (NIR), R (SWIR1) and R (SWIR2), where R is the reflectance at broad bands of the NIR, SWIR1 and SWIR2. For simplicity, the vertices will be referred in this study by their band location. SASI is calculated as product of the angle at SWIR1 and the inclination of the line ' $c$ ' that passes through the NIR and SWIR2 vertices. The slope of line 'c', (RSWIR2-RNIR) / ( $\lambda$ SWIR2- $\lambda$ NIR) can be approximated by the difference of the reflectance at NIR and SWIR 2 since the wavelength difference between the two vertices is constant. An advantage of angle indexes is that they are relatively insensitive to albedo differences for comparison between spectra.

Equations for calculating SASI are given below:

$$
\begin{aligned}
& \beta_{\text {SWIR1 }}=\cos ^{-1}\left(\frac{a^{2}+b^{2}-c^{2}}{2 a b}\right) \\
& \text { Slope }=(\text { SWIR2-NIR }) \\
& \text { SASI }=\beta_{\text {SWIRI } \times \text { Slope }}
\end{aligned}
$$

Where, $a, b$ and $c$ are euclidian distances between the vertices NIR and SWIR1 and SWIR2, and NIR and SWIR2, respectively. SASI and its parameters for different features are shown given in Table 2;

Table 2: SASI and its parameters for different features

\begin{tabular}{cccc}
\hline Features & BswiR1 & Slope & SASI \\
\hline Dry soil & High & High \& +ve & Highly +ve \\
Wet soil & Low & Small \& +ve & Low +ve \\
$\begin{array}{c}\text { Dry } \\
\text { vegetation } \\
\begin{array}{c}\text { Moist } \\
\text { vegetation }\end{array}\end{array}$ & Low & Small \& -ve & Low ve \\
\hline
\end{tabular}

The dry spells in the month of October (2001-2012) were assessed using SPI maps and the dry soil and dry vegetation in October month of each year was assessed using classified SASI maps. The interrelation between meteorological drought and agriculture stress during early-season was analyzed and the effectiveness of SASI in detecting early-season agriculture drought was tested. 


\section{RESULTS AND DISCUSSION}

\subsection{Meteorological Drought Assessment}

The analysis of monthly SPI values of the study area revealed the frequent occurrence of mild to severe meteorological drought over Aurangabad district in Early Rabi season of years 2001 to 2012. The SPI maps over the years in early Rabi season were prepared and it was observed that October months of year 2002, 2003, 2005, 2007 and 2011 are most drought prone periods (Figure 3).

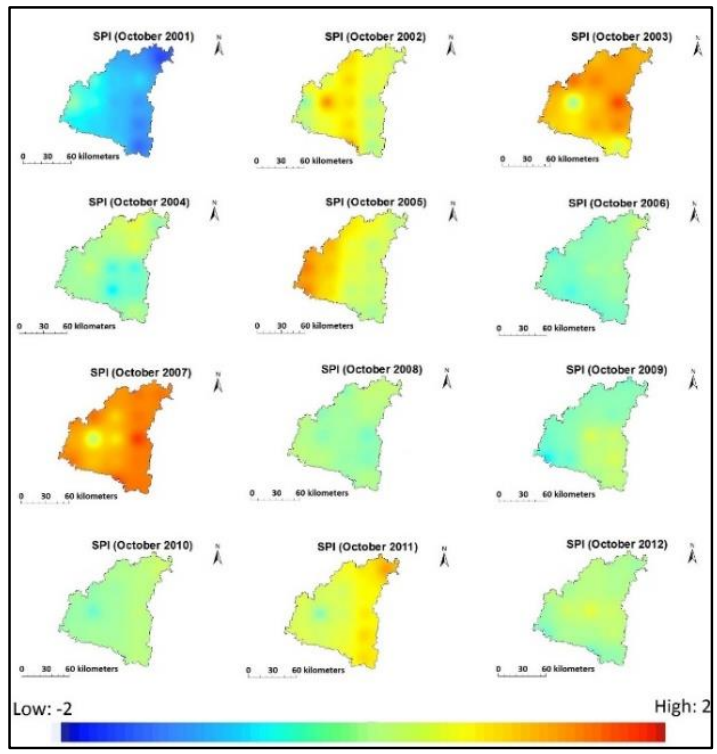

Figure 3: Early Rabi Season SPI Maps

Minimum and Maximum SPI values over the years in early Rabi season are given in Figure 4

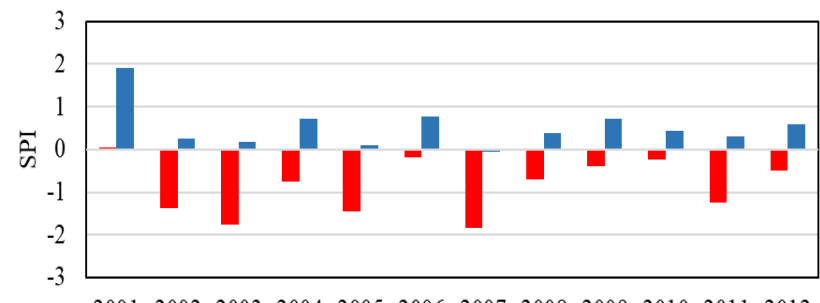

200120022003200420052006200720082009201020112012 Figure 4: Early Rabi Season Minimum and Maximum SPI value over the Years

\subsection{Assessment of Agriculture Drought}

SASI maps were generated using 8-day composites of MODIS $500 \mathrm{~m}$ images of NIR, SWIR1 and SWIR 2 bands. SASI is highly sensitive to rainfall and hence indirectly associated with crop sown area. SASI is capable of estimating surface moisture in the early part of the crop season in a better way than other indices like NDVI, NDWI, etc. SASI variations in the early season which represent dynamics of surface moisture were used for assessing the area favourable for crop sowing. SASI of the early Rabi season were computed and classified which shows the dry soil, moist soil, dry vegetation and moist vegetation (Figure 5). The SASI derived area under stress in different time period of October months were derived and it was observed 2001, 2002, 2003, 2007 and 2008 are the years where more than $50 \%$ area were under agricultural stress in the early Rabi season (Figures 6)
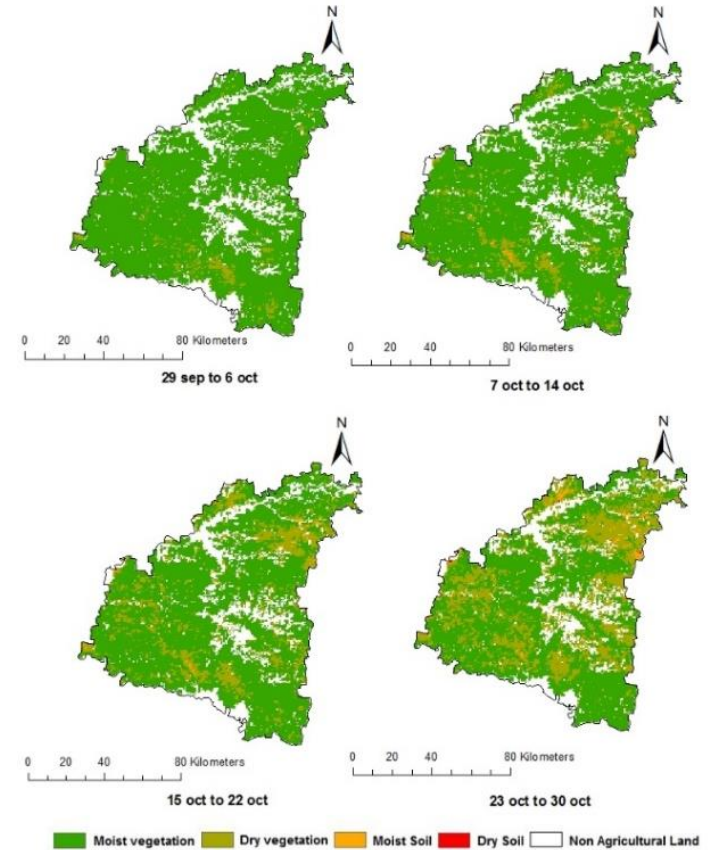

Figure 5: Early Rabi Season SASI Map of October 2012 derived using MODIS data

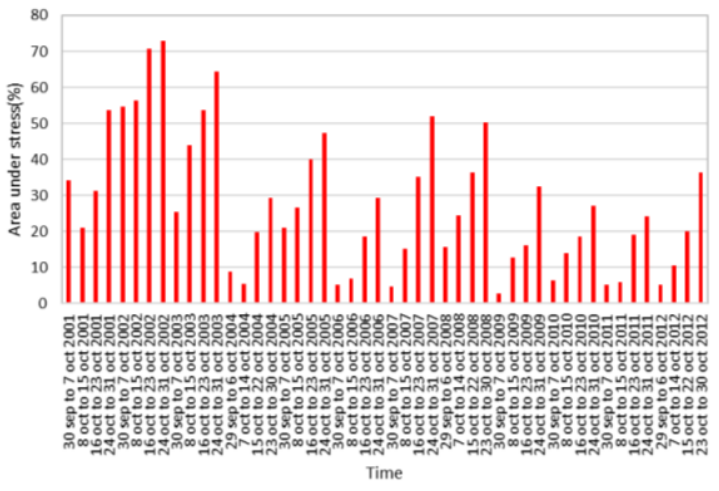

Figure 6. SASI Derived Area under Water Stress in the Early Rabi Season

\subsection{Sensitivity Analysis}

The variation of the SPI derived area under meteorological stress and maximum SASI derived area under stress in October month over the years were compared (Figure 7).

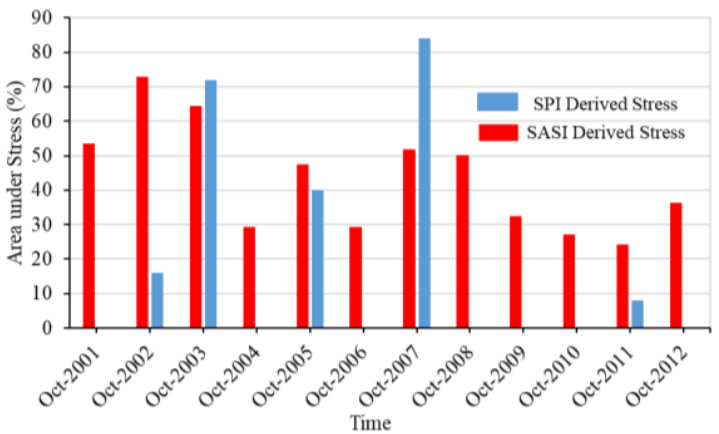

Figure 7. Early Rabi Season SPI and SASI Derived Area under Stress

Frequency of dryness/wetness in the study area in the early Rabi season was also computed (Figure 8). It was observed that many 
areas remain moist even if in the time of meteorological drought which indicates that these areas might be irrigation fed and other areas are rain fed.

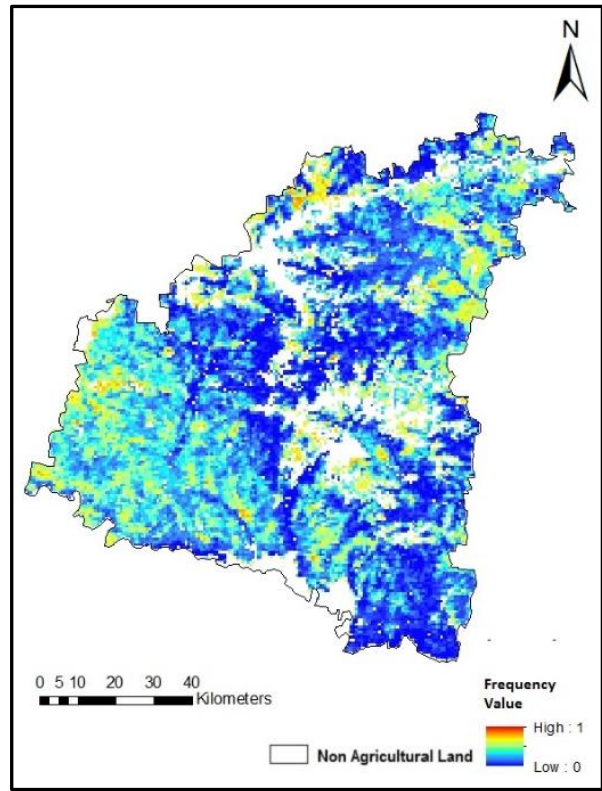

Figure 8. Early Rabi Season Dryness frequency Distribution Map

\section{CONCLUSION}

The main objective of this study was to detect early season dryness and wetness condition of the using remote sensing data and also identify the most affected areas from agricultural stress in the early season. An attempt was made to observe the meteorological stress and its impact on the surface moisture. Meteorological drought was assessed using SPI and shown for 12 years with the help of 30 years rainfall data, of the early Rabi season. SASI was also calculated for 12 years for the same time periods. It was observed that agricultural stress occurred even if there was no meteorological stress but most of the cases when the agricultural stress exceeds more than $50 \%$ area of the study region, meteorological stress was found to be the trigger. In the early Rabi season of 2003, 2005, 2007 were the identical years where we observed that there is a direct relationship of meteorological stress and agricultural stress. A dryness/wetness frequency distribution map was prepared from which we can identify areas with and without irrigation facility.

\section{REFERENCES}

Aswathi, P. V., Nikam, B. R., Chouksey, A., Aggarwal, S. P., 2018. Assessment and Monitoring of Agricultural Droughts in Maharashtra using Meteorological and Remote Sensing Based Indices. ISPRS Ann. Photogramm. Remote Sens. Spatial Inf. Sci., IV-5, 253-264.

Das, P.K., Murthy C, S., MVR, S., 2012. Monitoring of seasonal dryness/wetness conditions using shortwave angle slope index for early season agricultural drought assessment. Geomatics, Natural Hazards and Risk, 5(3), 232-251.

Dogan, S., Berktay, A., Singh, V.P., 2012. Comparison of multimonthly rainfall-based drought severity indices, with application to semi-arid Konya closed basin, Turkey. Journal of Hydrology 470-471, 255-268.
Gebrehiwot, T., Veen, A., Maathuis, B., 2011. Spatial and temporal assessment of drought in the Northern highlands of Ethiopia. International Journal of Applied Earth Observation and Geoinformation, 13, 309-321.

Gupta, A., Tyagi, P., Sehgal, V.K., 2011. Drought disaster challenges and mitigation in India: strategic appraisal. Current Science, 100 (12), 1795-1806.

Huang, S., Huang,Q., Chang,J., Leng, G., Xing, L., 2015. The response of agricultural drought to meteorological drought and the influencing factors: A case study in the Wei River Basin, China. Agricultural Water Management, 159, 45-54.

Huete, A., Didan, K., Miura, T., Rodriguez, E.P., Gao, X., Ferreira, L.G., 2002. Overview of the radiometric and biophysical performance of the MODIS vegetation indices. Remote Sensing of Environment, 83, 195-213.

Khanna, S., Palacios-Orueta, A., Whiting, M.L., Ustin, S.L., Riaño, D., Litago, J., 2007. Development of angle indexes for soil moisture estimation, dry matter detection and land-cover discrimination. Remote Sensing of Environment, 109, 154-165.

Leng, G., Tang, Q., Rayburg, S., 2015. Climate change impacts on meteorological, agricultural and hydrological droughts in China. Global and Planetary Change, 126, 23-34.

McKee, T., Doesken, N., Kleist, J., 1993. The relationship of drought frequency and duration to time scales. Applied Climatology, Am. Meteor. Soc. Boston, Anaheim, CA, 179-184.

Morid, S., Smakhtin, V., Moghaddasi, M., 2006. Comparison of Seven Meteorological Indices for Drought Monitoring in Iran. Int. J. Climatol. 26: 971-985.

Padhee, S. K., Nikam, B. R., Aggarwal, S. P. and Garg, V., 2014. Integrating Effective Drought Index (EDI) and Remote Sensing Derived Parameters for Agricultural Drought Assessment and Prediction in Bundelkhand Region of India. The International Archives of the Photogrammetry, Remote Sensing and Spatial Information Sciences (ISPRS), Xl-8, 89-100.

Padhee, S., Nikam, B. R., Dutta, S., Aggarwal S. P., 2017. Using satellite based soil moisture to detect and monitor spatiotemporal traces of agricultural drought over Bundelkhand region of India. GIScience Remote Sensing, 54(2), 144-166.

Palacios-Orueta, A., Khanna, S., Litago, J., Whiting, M. L., Ustin, S. L., 2006. Assessment of NDVI and NDWI spectral indices using MODIS time series analysis and development of a new spectral index based on MODIS shortwave infrared bands. Proceedings of the $1^{\text {st }}$ international conference of remote sensing and geoinformation processing (207-209 pp).

Rhee, J., Im,J., Carbone, G.J., 2010. Monitoring agricultural drought for arid and humid regions using multi-sensor remote sensing data. Remote Sensing of Environment, 114, 2875-2887.

Thom, H.C.S., 1958. A note on gamma distribution. Mon. Weather Rev., 86, 117-122.

Vangelis, H., Tigkas, D., Tsakiris, G., 2013. The effect of PET method on Reconnaissance Drought Index (RDI) calculation. Journal of Arid Environments, 88, 130-140.

Wilhite, D.A., 2002. Preparing for drought: a methodology. In:Wilhite, D.A. (Ed.), Drought: A Global Assessment. Hazards and Disaster Series, Routledge, New York, 2, 89-104.

Zarch, M.A.A., Sivakumar, B. Sharma, A. (2015). Droughts in a warming climate: A global assessment of Standardized precipitation index (SPI) and Reconnaissance drought index (RDI). Journal of Hydrology, 526, 183-195.

Zarch, M.A.A., Sivakumar, B., Sharma, A., 2015. Droughts in a warming climate: A global assessment of Standardized precipitation index (SPI) and Reconnaissance drought index (RDI). Journal of Hydrology, 526, 183-195. 